ГORIGINAL ARTICLE-

Volume 13 Issue 32021

DOI: 10.21315/eimj2021.13.3.6

ARTICLE INFO

Received: 02-01-2021

Accepted: 12-06-2021

Online: 30-09-2021

\section{Stress Factors and Depression Levels of International Medical Students in Bulgaria and Turkish Medical Students}

\author{
Merve Vatansever ${ }^{1}$, Elia Georgieva ${ }^{2}$, Angelika Velkova ${ }^{2}$ \\ ${ }^{1}$ Department of Forensic Psychology, Institute of Forensic Sciences, \\ Ankara University, Ankara, TURKEY \\ ${ }^{2}$ Department of Social Medicine, Faculty of Public Health, Medical \\ University of Sofia, Sofia, BULGARIA
}

To cite this article: Vatansever M, Georgieva E, Velkova A. Stress factors and depression levels of international medical students in Bulgaria and Turkish medical students. Education in Medicine Journal. 2021;13(3):55-64. https://doi.org/10.21315/eimj2021.13.3.6

To link to this article: https://doi.org/10.21315/eimj2021.13.3.6

\begin{abstract}
Throughout medical education, medical students are reported to experience high levels of stress and depression. The aim of this study was to compare the stress factors and depression levels of medical students in Bulgaria and Turkey. This cross-sectional comparative study included 546 students (276 international students from abroad studying at the Medical University of Sofia in Bulgaria and 270 Turkish medical students). The questionnaire consisted of sociodemographic questions, a Medical Student Stressor Questionnaire (MSSQ-40 items), and a Beck Depression Inventory (BDI). The Turkish pre-clinical and clinical students had higher levels of stress and depression than the international pre-clinical medical students in Bulgaria. When the medical students were compared, $51.4 \%$ of the international medical students in Bulgaria and $28.5 \%$ of the Turkish medical students were found to be without depression. Moreover, $26.7 \%$ of the Turkish medical students and $12 \%$ of the international medical students in Bulgaria had moderate levels of depression. In addition, each domain of the MSSQ had a relationship with depression in both groups of medical students, with the exception of one domain (intrapersonal and interpersonal related stressors), which had no significant relationship with the depression scores of the Turkish clinical students. The findings of our study imply that medical students may need psychological support throughout their education, and this applies especially to Turkish medical students. Knowing the stress factors and depression levels that medical students experience plays an important role in determining the approaches to adopt to them.
\end{abstract}

Keywords: Depression, Medical education, Medical student, Stress

Merve Vatansever, Department of Forensic Psychology, Institute of Forensic Science, Ankara University, Cebeci Research and Application Hospital, 06590 Ankara, TURKEY

Email: mervevatansever.tr@gmail.com

\section{INTRODUCTION}

According to research studies from various countries worldwide, medical education is inherently demanding and stressful (1-4). High levels of psychological distress have been found in medical students in Spain (5), Romania (6), Bulgaria (7), Canada (8), Turkey (9), Australia (1), Egypt (2, 10), India (11), Malaysia (12), Pakistan (13), Poland (4) and Korea (3). 
Selye (14) has defined stress as the body's non-specific response to any demand. A stressor is a stress that causes personal and environmental events (14). Various sources of stress can affect medical students during their medical education. One of the most important sources of stress is academicrelated stressors. Academic-related stressors include tests or examinations, too much content to be learnt, heavy workloads, falling behind on work and receiving poor marks. In addition, students are affected by interpersonal interactions with both other students and their teachers (15-16). The clinical year may include additional stress factors, such as communicating with dying patients and confronting death (17). It is not known whether the personal problems experienced by students have any effect on their academic success and psychological disturbances (18).

Medical students begin to experience stress during their first-year of education (15). The first-year marks a transition to a new period in their lives, in which their environment changes and new information is learned (19). During their second-year and third-year, students receive a broad and intensive education in pre-clinical courses. In the process of transition from pre-clinical to clinical education, the students learn how to approach patients and engage with them in practice. In their third-year and fourth-year of medical education, students tend to feel more depressed as a result of rotating through hospitals and clinics (20). During this period, students may feel that they lack sufficient knowledge and skills to apply their training to practical situations. In their fifth-year and sixth-year, students are more advanced and better able to approach patients. However, although their competency levels have increased, they feel much more anxiety (21). Most studies have shown that medical students experience most stress, and have a higher prevalence of depression and low life satisfaction during their second-year $(9,22)$ and third-year $(23-$ 24).
Research indicates that depression is associated with the stress experienced by medical students. In fact, it is thought that depression in medical students may be caused by stress, and there is evidence that such depression remains undiagnosed and untreated (25). In addition to depression, anxiety (9), burnout (8, 26-27), suicidal thoughts (25) and substance abuse (21) are other psychological problems seen among medical students. It is necessary to increase awareness among medical students of the problems stress causes to mental health, especially depression and to ensure that they get help when necessary.

The prevalence of depression among firstyear and second-year medical students in the United States was found to be $24 \%$ (28), while approximately $35 \%$ of Malaysian medical students were depressed (29) and the prevalence in Egypt was about 23\% (2). However, studies comparing depression levels among medical students at different academic levels were inconsistent. There was no significant difference between firstyear and final-year medical students with regard to depression (30). Nevertheless, another study found differing levels of depression among pre-clinical, clinical and intern medical students (31). In addition, depression differed among first-year and second-year medical students in Turkey (9).

Perceived stress varies across cultures. Students from individualist cultures have been found to have lower levels of perceived stress than students raised in collectivist cultures (32-33). Family and in-group members are important for individuals in collectivist cultures, which have strong communication, insist on maintaining harmony and avoiding conflicts and view the aim of education as being learning how to do something rather than how to learn it (34). Turkey is known to be a collectivist country and Bulgaria has also been considered a collectivist culture (35). However, students from many European countries come to Bulgaria to study 
medicine. This intercultural study compares these students from Western cultures (individualistic culture) with Turkish students (collectivistic culture) with regard to their levels of stress and depression.

The main aim of this study was to determine whether there is a significant difference between international medical students studying in Bulgaria and Turkish medical students when it comes to stress factors and depression levels. The study also sought to reveal the relationship between stress factors and depression in medical students. In this way, the study aimed to fill the gap in the literature by comparing international students studying medicine in a foreign country and medical students studying in their own country.

\section{METHODS}

\section{Participants}

A cross-sectional comparative study was conducted in the fall semester of the 2019-2020 academic year in Turkey and Bulgaria. The sample of the study consisted of a total of 546 students; 270 of whom were Turkish medical students (46.3\% pre-clinical, $53.7 \%$ clinical), and 276 of whom were international students $(79.7 \%$ in second-year and $20.3 \%$ in third-year). They were studying medicine in English at the Medical University of Sofia (Table 1). All the Turkish medical students were from public universities in Ankara, Turkey (45.6\% were from Ankara University, $43 \%$ were from Sağlık Bilimleri University, $6.7 \%$ were from Gazi University and $4.8 \%$ were from Hacettepe University). Turkish students studying at public universities in Turkey do not pay any fees. In addition, 276 international medical students at the Medical University of Sofia also participated. These students had come from abroad to study medicine in Bulgaria and paid a certain fee.

\section{Instruments}

The study instrument consisted of basic demographic questions, with 21 questions to investigate the prevalence of depression (Beck Depression Inventory [BDI]) and 40 questions to investigate stress (Medical Student Stressor Questionnaire [MSSQ]).

\section{The MSSQ}

The MSSQ was developed by Yusoff et al. (36) in order to determine the prevalence and levels of stress and stressors in medical students. The questionnaire consists of 40 items and each item is rated according to a score of $0-4(0=$ no stress at all, $1=$ mild stress, $2=$ moderate stress, $3=$ high stress, and $4=$ severe stress). It has six stressor groups such as, academic related stressors (ARS), intrapersonal and interpersonal related stressors (IRS), teaching and learning related stressors (TLRS), social related stressors (SRS), drive and desire related stressors (DRS) and group activities related stressors (GARS). The mean domain score of each stressor group is determined as follows: $0.00-1.00=$ mild, $1.01-2.00=$ moderate, $2.01-3.00=$ high and 3.01-4.00 $=$ severe. $\mathrm{A}$ mild score means that someone experiences no stress. A moderate score indicates a reasonable and manageable level of stress. A high score indicates that someone experiences a great deal of stress and that this affects their daily activities in a mild way. A severe score means that someone experiences severe stress and that this adversely affects their daily activities. The Cronbach's alpha of the total MSSQ was found to be 0.96 in the current study.

\section{The BDI}

The BDI is a self-assessment scale consisting of 21 items that evaluate the somatic, emotional, cognitive and motivational symptom clusters in depression. Each item evaluating a symptom of depression is scored on a four-point scale and a total depression score of 0-63 
is obtained from the scale. The score obtained provides information about the severity of the depression symptoms. If the total depression score is above 17, the symptoms of depression are considered to be high (37). The cut-off points for the BDI are as follows: $0-9$ indicates no or minimal depression, 10-18 indicates mild depression, 19-29 indicates moderate depression and 30-63 indicates severe depression (38). The Cronbach's alpha of the total BDI was found to be 0.89 in the current study.

\section{Procedure}

Ethics committee approval was obtained from the Ankara University Ethics Committee (ref. 56786525-050 .04.04/77660). Informed consent was obtained from the participants. Data were collected using Google Forms. The link to the research study was shared with the students through snowball sampling. The data were statistically analysed using SPSS version 20.0. Mean, standard deviation (SD) and frequency were used for the descriptive statistics. Chi-square $\left(\chi^{2}\right)$ analysis was used to compare categorical variables. The study sample did not show normal distribution and the KruskalWallis test was therefore used to compare three groups. A correlation analysis was conducted to investigate the relationship between depression and stressors using a significance level of $p<0.05$.

\section{RESULTS}

Table 1 presents the demographic characteristics of the population studied. About $168(62.2 \%)$ of the Turkish students were female and $158(57.2 \%)$ of the international students at the Medical University of Sofia were female. There was no difference between the Turkish and international students with regard to gender $\left(\chi^{2}=1.41, p=0.236\right)$. The Turkish medical students had a mean age of 21.07 $(\mathrm{SD}=1.99)$ years, while the international medical students in Bulgaria had a mean age of $20.89(\mathrm{SD}=2.65)$ years.

When comparing the stress levels of the Turkish medical students and the international medical students in Bulgaria, it was taken into consideration that the Turkish students participating included students from the first-year to the final-year. Turkish medical students were grouped as pre-clinical from first-year to third-year and as clinical year from fourth-year to

Table 1: Demographic characteristics of the sample

\begin{tabular}{|c|c|c|c|c|c|}
\hline \multirow[t]{2}{*}{ Variable } & \multicolumn{2}{|c|}{$\begin{array}{l}\text { Turkish medical students } \\
\qquad(N=270)\end{array}$} & \multicolumn{2}{|c|}{$\begin{array}{c}\text { International medical } \\
\text { students in Bulgaria } \\
(N=276)\end{array}$} & \multirow[t]{2}{*}{$\chi^{2}$} \\
\hline & $n$ & $\%$ & $n$ & $\%$ & \\
\hline Gender & & & & & 1.41 \\
\hline Female & 168 & 62.20 & 158 & 57.20 & \\
\hline Male & 102 & 37.80 & 118 & 42.80 & \\
\hline Total & 270 & 100.00 & 276 & 100.00 & \\
\hline \multicolumn{6}{|l|}{ Year } \\
\hline Pre-clinical (first-year to third-year) & 125 & 46.30 & 276 & 100.00 & - \\
\hline Clinical (fourth-year to sixth-year) & 145 & 53.70 & - & - & - \\
\hline \multicolumn{6}{|l|}{ Age } \\
\hline Mean & \multicolumn{2}{|c|}{21.07} & \multicolumn{2}{|c|}{20.89} & - \\
\hline SD & \multicolumn{2}{|c|}{1.99} & \multicolumn{2}{|c|}{2.65} & - \\
\hline
\end{tabular}


sixth-year, and the second-year and thirdyear students in Bulgaria were grouped as pre-clinical. The Kruskal-Wallis test was used to compare these three groups because the MSSQ scores of the students were not normally distributed. There were missing data among the international medical students in Bulgaria, resulting in a variation in the number of samples in each domain of the MSSQ. A Kruskal-Wallis test revealed a statistically significant difference in each domain of the MSSQ across the three students groups (ARS $\chi^{2}=87.63$, $p<0.001$; IRS $\chi^{2}=140.4, p<0.001$; TLRS $\chi^{2}=47.67, p<0.001$; SRS $\chi^{2}=86.70$, $p<0.001$; DRS $\chi^{2}=56.61, p<0.001$; GARS $\left.\chi^{2}=89.05, p<0.001\right)$. The results are shown in Table 2 .

Since we obtained a statistically significant result for the Kruskal-Wallis test, MannWhitney $U$ test were conducted between pairs of groups (e.g., between the Turkish pre-clinical students and the international pre-clinical students in Bulgaria) to discover which of the groups were significantly statistically different from one another. Mann-Whitney $U$ test revealed a statistically significant difference in all domains of stressors across the Turkish pre-clinical and the international pre-clinical students in Bulgaria, as well as among the Turkish clinical and the international pre-clinical students in Bulgaria. As a result, the Turkish pre-clinical and clinical students showed higher stress in each domain than the international pre-clinical students in Bulgaria. When comparing the Turkish preclinical and clinical students, there was no significant difference in terms of SRS and DRS. For the rest of the stressor domains, the Turkish clinical students had more stress than the pre-clinical students.

The Turkish medical students' mean score for the BDI was 15.26 (SD = 8.71), while the mean of the international medical students in Bulgaria was 11.61 ( $S D=9.52)$. A $\chi^{2}$ test was applied to determine whether there was a difference between the preclinical and clinical Turkish medical students with regard to depression levels and no significant difference was found $\left(\chi^{2}=\right.$ $7.78, p=0.51)$. A $\chi^{2}$ test for independence indicated a significant association between studying medicine in different countries and depression levels $\left(\chi^{2}=35.55, p<0.001\right)$. About $51.4 \%$ of the international medical students in Bulgaria did not experience depression, in comparison to $28.5 \%$ of Turkish medical students. Around 26.7\% of the Turkish medical students had a moderate depression level, while $12 \%$ of the international medical students in Bulgaria experienced moderate depression (Table 3).

Table 2: Results of Kruskal-Wallis test scores of MSSQ subgroups of international pre-clinical medical students in Bulgaria, pre-clinical and clinical Turkish medical students

\begin{tabular}{|c|c|c|c|c|c|c|c|c|c|c|}
\hline \multirow[t]{2}{*}{$\begin{array}{l}\text { Stress } \\
\text { domain }\end{array}$} & \multicolumn{3}{|c|}{$\begin{array}{l}\text { Turkish pre-clinical } \\
\text { students }\end{array}$} & \multicolumn{3}{|c|}{$\begin{array}{l}\text { Turkish clinical } \\
\text { students }\end{array}$} & \multicolumn{3}{|c|}{$\begin{array}{c}\text { International } \\
\text { pre-clinical students } \\
\text { in Bulgaria }\end{array}$} & \multirow[t]{2}{*}{$\chi^{2}$} \\
\hline & $n$ & Median & IQR & $n$ & Median & IQR & $n$ & Median & IQR & \\
\hline ARS & 125 & 2.61 & 1.54 & 145 & 2.92 & 1.19 & 250 & 1.85 & 1.33 & $87.63^{* *}$ \\
\hline IRS & 125 & 2.14 & 1.71 & 145 & 2.43 & 1.43 & 260 & 1.00 & 1.29 & $140.41^{* *}$ \\
\hline TLRS & 125 & 1.86 & 1.50 & 145 & 2.28 & 1.36 & 265 & 1.43 & 1.29 & $47.67^{* *}$ \\
\hline SRS & 125 & 1.83 & 1.17 & 145 & 2.00 & 0.83 & 253 & 1.17 & 1.00 & $86.70^{* *}$ \\
\hline DRS & 125 & 1.67 & 1.67 & 145 & 1.67 & 1.33 & 268 & 1.00 & 1.33 & $56.61^{* *}$ \\
\hline GARS & 125 & 2.00 & 1.50 & 145 & 2.50 & 1.25 & 272 & 1.25 & 1.50 & $89.05^{* *}$ \\
\hline
\end{tabular}

Notes: ${ }^{* *} p<0.001 ; \mathrm{IQR}=$ Inter quartile range. 
Table 3: Results of the $\chi^{2}$ test concerning BDI of international students in Bulgaria and Turkish medical students

\begin{tabular}{|c|c|c|c|c|c|}
\hline \multirow[t]{2}{*}{ Depression levels } & \multicolumn{2}{|c|}{$\begin{array}{l}\text { Turkish medical students } \\
\qquad(N=270)\end{array}$} & \multicolumn{2}{|c|}{$\begin{array}{l}\text { International medical students } \\
\text { in Bulgaria }(N=276)\end{array}$} & \multirow{2}{*}{$\chi^{2}$} \\
\hline & $n$ & $\%$ & $n$ & $\%$ & \\
\hline Without depression & 77 & 28.5 & 142 & 51.4 & $35.55^{* *}$ \\
\hline Mild & 104 & 38.5 & 86 & 31.2 & \\
\hline Moderate & 72 & 26.7 & 33 & 12.0 & \\
\hline Severe & 17 & 6.3 & 15 & 5.4 & \\
\hline
\end{tabular}

Note: ${ }^{* *} p<0.001$.

Table 4: Intercorrelations between BDI total scores and stress domains of MSSQ of the Turkish pre-clinical and clinical students and international pre-clinical students in Bulgaria

\begin{tabular}{lccc} 
Stress domain & $\begin{array}{c}\text { Turkish pre-clinical } \\
\text { students }\end{array}$ & $\begin{array}{c}\text { Turkish clinical } \\
\text { students }\end{array}$ & $\begin{array}{c}\text { International pre-clinical } \\
\text { students in Bulgaria }\end{array}$ \\
\hline ARS & $0.50^{* *}$ & $0.28^{* *}$ & $0.35^{* *}$ \\
IRS & $0.41^{* *}$ & 0.11 & $0.27^{* *}$ \\
TLSR & $0.48^{* *}$ & $0.20^{*}$ & $0.30^{* *}$ \\
SRS & $0.34^{* *}$ & $0.26^{* *}$ & $0.20^{* *}$ \\
DRS & $0.47^{* *}$ & $0.24^{* *}$ & $0.30^{* *}$ \\
GARS & $0.51^{* *}$ & $0.32^{* *}$ & $0.34^{* *}$ \\
\hline
\end{tabular}

Note: ${ }^{* *} p<0.01 ;{ }^{*} p<0.05$.

The correlation results of the BDI and stress domains of the MSSQ are provided in Table 4. There was a positive relationship between depression and all the stress domains in the Turkish pre-clinical and clinical students and in the international pre-clinical students in Bulgaria. The only exception was that there was no significant difference between depression score and IRS in the Turkish clinical students.

\section{DISCUSSION}

In summary, the current study found that the Turkish pre-clinical and clinical students had higher stress levels than the international pre-clinical medical students in Bulgaria. Additionally, the Turkish medical students were more depressed than the international students in Bulgaria. In line with previous research, all the types of stressors experienced by the medical students had a relationship with depression (29).

With regard to ARS, we see that the Turkish clinical students experienced more stress than both the Turkish pre-clinical and the international pre-clinical students in Bulgaria. It was reported that the students felt more stress as they progressed in the education process (39). It is to be expected that the workload and medical skill practice would be heavier in the clinical years, in comparison to the pre-clinical years. However, some studies report that students in the pre-clinical years experience higher stress (40). The stress scores of the Turkish pre-clinical medical students were found to be higher than those of the international pre-clinical medical students in Bulgaria. Consistent with the literature, the Turkish medical students from a collectivist culture 
perceived higher levels of stress than the students from western cultures (32-33). One possible reason for the Turkish preclinical students experiencing higher stress than the international pre-clinical students in Bulgaria could be their more competitive environment. International pre-clinical students in Bulgaria receive a paid-for education in English and return home after graduation. It is therefore possible to argue that they will experience less competition among students in their in-group setting (41) and that they will provide academic support for each other. International students support each other in terms of the evaluation, gathering, analysis of the information called information processing support (42). This is confirmed by the scores of both the IRS and GARS of the international pre-clinical students in Bulgaria, which were lower than the scores of the Turkish medical students. This shows that the international pre-clinical students in Bulgaria experienced fewer conflicts with other students. In addition, when considering other questions related to the content of the IRS, it can be said that the Turkish medical students experienced more conflict with their teachers and other personnel. It is to be expected that the problems, conflicts, and even verbal and physical abuse experienced by students in their relations with other people increase their stress levels and this situation makes them more vulnerable to depression (43). Furthermore, one can assume that the international medical students in Bulgaria, who pay a significant amount for their education, do not have financial concerns. It is acknowledged that financial difficulties negatively affect the academic life of students by providing increased stressors (44).

The difference in SRS and DRS may stem from cultural differences, which play a role in these stress factors and include familial expectations and responsibilities. It is possible to argue that the collectivist culture is more dominant in Turkish culture (35), which means that responsibilities towards one's family are at the forefront. Culturally, Turkish students may feel more responsible towards their families and think that they should strive to meet their expectations. In parallel with this explanation, no significant difference was found between Turkish preclinical and clinical students in relation to these stress factors. Cultural differences can also be noted in relation to this stress factor, which involves communicating with patients, such as talking to patients about their problems and answering their questions. The importance of what others say to you in relationships with other people in collectivist culture affects interpersonal interaction.

A previous study that compared Bulgarian medical students and international medical students studying in Bulgaria found no significant difference with regard to depression levels (45). In the current study, the depression levels of the Turkish medical students were higher than those of the international medical students in Bulgaria. In addition, no difference in depression levels was found between the Turkish preclinical and clinical students. It is possible that high stress levels also affected the levels of depression in the Turkish medical students. Academic, interpersonal, grouprelated and learning-related stressors make students more depressed (31). Among the reasons for the higher depression levels found in the Turkish medical students were one can include future anxiety, economic factors and finding a job after graduation. In order to better understand the depressive states of medical students, interviews using a qualitative research design that provide more detailed information are recommended.

\section{CONCLUSION}

The limitations of the study should be considered when evaluating its findings. This study was based on results from a self-reported online questionnaire. With online data collection, only second-year 
and third-year student were reached in Bulgaria. Moreover, there was insufficient data to compare socioeconomic status. The international medical students in Bulgaria paid for their education, while all the Turkish students in the current sample were from public universities. The differences in the levels of stress and depression between the Turkish students and the international students in Bulgaria could be explained by a combination of factors, including cultural, socioeconomic and personal factors. Further studies involving Bulgarian medical students or international medical students in Turkey are needed for a better understanding of these difference. In addition, qualitative studies using an interview method are needed to better explain the levels of depression in medical students. Moreover, when comparing stress factors in collectivist and individualist cultures, strategies for coping with stress should also be considered.

\section{REFERENCES}

1. Bore M, Kelly B, Nair B. Potential predictors of psychological distress and well-being in medical students: a crosssectional pilot study. Adv Med Educ Pract. 2016;7:125-35. https://doi.org/10.2147/ AMEP.S96802

2. Fawzy M, Hamed SA. Prevalence of psychological stress, depression and anxiety among medical students in Egypt. Psychiatry Res. 2017;255:186-94. https:// doi.org/10.1016/j.psychres.2017.05.027

3. Park KH, Kim DH, Kim SK, Yi YH, Jeong JH, Chae J, et al. The relationships between empathy, stress and social support among medical students. Int J Med Educ. 2015;6:103-8. https://doi.org/10.5116/ijme $.55 \mathrm{e} 6.0 \mathrm{~d} 44$

4. Rosiek A, Rosiek-Kryszewska A, Leksowski Ł, Leksowski K. Chronic stress and suicidal thinking among medical students. Int J Environ Res Public Health. 2016;13(2):116. https://doi.org/10.3390/ijerph13020212
5. Sender R, Salamero $M$, Vallés A, Valdés M. Psychological variables for identifying susceptibility to mental disorders in medical students at the University of Barcelona. Med Educ Online. 2004;9(1):43-50. https://doi.org/10.3402/meo.v9i.4350

6. Bob MH, Popescu CA, Pîrlog R, Buzoianu AD. Personality factors associated with academic stress in first year medical students. Human and Veterinary Medicine. 2014;6(1):40-4.

7. Georgieva EK, Georgieva LM, Zahariev VS, Pesheva PA. Stress and stress factors among medical students in Bulgaria. Albanian Med J. $2014 ; 28(1): 10-7$.

8. Dyrbye LN, Thomas MR, Shanafelt TD. Systematic review of depression, anxiety, and other indicators of psychological distress among US and Canadian medical students. Acad Med. 2006;81(4):354-73.

9. Aktekin M, Karaman T, Senol YY, Erdem S, Erengin H, Akaydin M. Anxiety, depression and stressful life events among medical students: a prospective study in Antalya, Turkey. Med Educ. 2001;35(1):12-7. https://doi.org/10.1111/j .1365-2923.2001.00726.x

10. Amr M, El Gilany AH, El-Hawary A. Does gender predict medical students' stress in Mansoura, Egypt? Med Educ Online. 2008;13(1):4481. https://doi.org/10.3402/ meo.v13i.4481

11. Gupta S, Choudhury S, Das M, Mondol A, Pradhan R. Factors causing stress among students of a Medical College in Kolkata, India. Educ Health. 2015;28(1):92-5. https://doi.org/10.4103/1357-6283.161924

12. Sherina MS, Rampal L, Kaneson N. Psychological stress among undergraduate medical students. Med J Malaysia. 2004;59(2):207-11.

13. Sohail N. Stress and academic performance among medical students. J Coll Physicians Surg Pak. 2013;23(1):67-71. 
14. Selye H. Stress without distress. New York: Signet Book; 1974.

15. Dyrbye LN, Thomas MR, Shanafelt TD. Medical student distress: causes, consequences, and proposed solutions. Mayo Clin Proc. 2005;80(12):1613-22. https://doi.org/10.4065/80.12.1613

16. Yusoff MSB, Rahim AFA, Yaacob MJ. Prevalence and sources of stress among Universiti Sains Malaysia medical students. Malays J Med Sci. 2010;17(1):30-7.

17. Binienda J, Schwartz K, Gaspar D. Training in end-of-life care through interaction with dying patients. Acad Med. 2001;76(5):51729.

18. Saipanish R. Stress among medical students in a Thai medical school. Med Teach. 2003;25(5):502-6. https://doi.org/ $10.1080 / 0142159031000136716$

19. Tchen G, Carter A, Gibbons P, McLaughlin P. What is the relationship between indicators of stress and academic performance in first year university students? A prospective study. Journal of Institutional Research. 2001;10(2):1-12.

20. Rosenthal JM, Okie S. White coat, mood indigo-depression in medical school. N Engl J Med. 2005;353(11):1085-8.

21. Melaku L, Mossie A, Negash A. Stress among medical students and its association with substance use and academic performance. Journal of Biomedical Education. 2015;2015:1-9. https://doi.org/ $10.1155 / 2015 / 149509$

22. Clark DC, Zeldow PB. Vicissitudes of depressed mood during four years of medical school. JAMA. 1988;260(17):2521-8. https://doi.org/10.1001/jama.1988.0341017 0069036
23. Kjeldstadli K, Tyssen R, Finset A, Hem E, Gude T, Gronvold NT, et al. Life satisfaction and resilience in medical school-a six-year longitudinal, nationwide and comparative study. BMC Med Educ. 2006;6(1):48. https://doi.org/10.1186/1472 $-6920-6-48$

24. Mosley TH, Perrin SG, Neral SM, Dubbert PM, Grothues CA, Pinto BM. Stress, coping, and well-being among third-year medical students. Acad Med. 1994;69(9):765-7. https://doi.org/10.1097/ 00001888-199409000-00024

25. Tyssen R, Vaglum P, Grønvold NT, Ekeberg O. Suicidal ideation among medical students and young physicians: a nationwide and prospective study of prevalence and predictors. J Affect Disord. 2001;64(1):6979. https://doi.org/10.1016/S0165-0327(00) 00205-6

26. Dahlin ME, Runeson B. Burnout and psychiatric morbidity among medical students entering clinical training: a three year prospective questionnaire and interview-based study. BMC Med Educ. 2007;7(1):6. https://doi.org/10.1186/1472 $-6920-7-6$

27. Guthrie E, Black D, Bagalkote H, Shaw C, Campbell M, Creed F. Psychological stress and burnout in medical students: a five-year prospective longitudinal study. J R Soc Med. 1998;91(5):237-43. https://doi .org/10.1177/014107689809100502

28. Givens JL, Tjia J. Depressed medical students' use of mental health services and barriers to use. Acad Med. 2002;77(9):91821.

29. Saravanan C, Wilks R. Medical students' experience of and reaction to stress: the role of depression and anxiety. ScientificWorldJournal. 2014;2014:737382. https://doi.org/10.1155/2014/737382 
30. Bassols AM, Okabayashi LS, Silva ABD, Carneiro BB, Feijó F, Guimarães GC, et al. First-and last-year medical students: is there a difference in the prevalence and intensity of anxiety and depressive symptoms? Revista Brasileira de Psiquiatria. 2014;36(3):23340. https://doi.org/10.1590/1516-4446-2013 $-1183$

31. Baldassin S, Silva N, Alves TCDTF, Castaldelli-Maia JM, Bhugra D, NogueiraMartins MCF, et al. Depression in medical students: cluster symptoms and management. J Affect Disord. 2013;150(1):110-14. https://doi.org/10 $.1016 /$ j.jad.2012.11.050

32. Bailey FJ, Dua J. Individualismcollectivism, coping styles, and stress in international and Anglo-Australian students: a comparative study. Australian Psychologist. 2007;34(3):177-82. https://doi .org/10.1080/00050069908257451

33. Popa B, Guillet L, Mullet E. Cultural differences in the appraisal of stress. Psicológica. 2014;35(3):745-60.

34. Davidkov T. Where does Bulgaria stand. Papeles del este. 2004;8(1):1-22.

35. Hofstede G. Culture's consequences: international differences in work-related values. Beverly Hills. CA: Sage Publications; 1980.

36. Yusoff MSB, Rahim AFA, Yaacob MJ. The development and validity of the medical student stressor questionnaire. ASEAN Journal of Psychiatry. 2010;11(1):231-5.

37. Beck AT, Ward C, Mendelson M, Mock J, Erbaugh J. Beck depression (BDI). Arch Gen Psychiatry. 1961;4(6):561-71.

38. Beck AT, Steer RA, Carbin MG. Psychometric properties of the beck depression inventory: twenty-five years of evaluation. Clinical Psychology Review. 1988;8(1):77-100. https://doi.org/10.1016/ 0272-7358(88)90050-5
39. Bjorksten O, Sutherland S, Miller C, Stewart T. Identification of medical student problems and comparison with those of other students. J Med Educ. 1983;58(10):759-67.

40. Yee LY, Yusoff MSB. Prevalence and sources of stress among medical students in Universiti Sains Malaysia and Universiteit Maastricht. Education in Medicine Journal. 2013;5(4):34-41. https://doi.org/10.5959/ eimj.v5i4.190

41. Esses VM, Dovidio JF, Jackson LM, Armstrong TL. The immigration dilemma: the role of perceived group competition, ethnic prejudice, and national identity. Journal of Social Issues. 2001;57(3):389412. https://doi.org/10.1111/0022-4537 .00220

42. Dennis AR, Wixom BH, Vandenberg RJ. Understanding fit and appropriation effects in group support systems via meta-analysis. MIS Quarterly. 2001;25(2):167-93. https://doi.org/10.2307/3250928

43. Richman JA, Flaherty JA, Rospenda KM, Christensen ML. Mental health consequences and correlates of reported medical student abuse. JAMA. 1992;267(5):692-4. https://doi.org/10.1001/ jama.1992.03480050096032

44. Reid M, Jessop DC, Miles E. Explaining the negative impact of financial concern on undergraduates' academic outcomes: evidence for stress and belonging as mediators. Journal of Further and Higher Education. 2019:1-31. https://doi.org/10.10 80/0309877X.2019.1664732

45. Georgieva E, Velkova A, Dimitrova D. Comparative study of depression among Bulgarian and foreign medical students in the Medical University - Sofia. Health Policy and Management. 2020;20(2):33-8. (in Bulgarian) 